\title{
Intellectual function and age of repair in cyanotic congenital heart disease
}

\author{
R K Oates, J M Simpson, T B Cartmill, J A B Turnbull
}

\begin{abstract}
Eighty one children, comprising 51 with tetralogy of Fallot and 30 children with transposition of the great arteries (TGA) were assessed using the Wechsler intelligence scale for children - revised, and a battery of neuropsychological measures. They were compared with a group of 33 children who had surgery for ventricular septal defect. All children were aged over 10 years when reviewed and were in good health, attending normal schools. No significant negative correlation was found between any component or subtest of the IQ scores and operating age. There was no evidence of a detrimental effect of older age at operation in the children who had cyanotic heart disease as assessed by neuropsychological measures. Delaying surgery for children with TGA or tetralogy of Fallot does not appear to adversely affect their intellectual development. This finding may provide reassurance in cases where surgery has to be delayed for medical, social, or economic reasons.
\end{abstract}

(Arch Dis Child 1995; 72: 298-301)

Keywords: hypoxia, intelligence, congenital heart disease.

Chronic hypoxia in adults has been shown to be associated with impairment in memory and abstract reasoning, ${ }^{12}$ although the effects of chronic illness and increasing age may be confounding factors. In the 1960 s several papers which studied the abilities of children with cyanotic congenital heart disease found that, compared with non-cyanotic children, the cyanotic children were behind in gross motor skills, perceptual motor skills, visual reaction time, and had lower IQ scores, ${ }^{3-7}$ although it was suggested that the greater physical incapacity in the cyanotic children may have been a factor contributing to their lower test scores. ${ }^{5}$

O'Dougherty et al looked specifically at 31 children with transposition of the great arteries (TGA) who had been chronically hypoxic until surgery at a mean age of 2.0 years. $^{89}$ Compared with healthy controls, there was a higher incidence of discrepancy between the verbal and performance scores on the Wechsler intelligence scale for children revised (WISC-R). ${ }^{10}$ The main deficit in the cyanotic group was in freedom from distractibility. ${ }^{11}$ They found that, while the cyanotic group had a higher incidence of lower IQ than the controls, there were also more cyanotic children functioning in the superior range and above. When children who had a cerebrovascular accident or central nervous system infection were excluded, there was still a significant negative correlation between age of corrective surgery and IQ scores, suggesting that longer periods of chronic hypoxia may reduce intelligence.

Newburger et al studied 38 children who had reached a mean age of 5.8 years and who had corrective surgery for TGA at a mean age of 1.6 years. ${ }^{12}$ They were compared with 23 children who had ventricular septal defect (VSD) repaired at a mean age of 3.4 years. Those children with TGA who had acquired central nervous system damage were excluded. While the mean IQ of the group with TGA was normal (102) and similar to that of the VSD group, the children with TGA had lower scores on the geometric design of the subtest of the Wechsler preschool and primary scale of intelligence (WPPSI) ${ }^{13}$ than the population norms and the children with VSD. They also found an inverse relationship between age of repair and IQ in the cyanotic group, a finding that was not present in the children who had a VSD repair.

We had the opportunity, nine to 10 years after corrective surgery, to study a large group of children who had cyanotic and acyanotic congenital heart disease with the aim of seeing whether, at this age, there was any evidence of a relationship between the age of corrective surgery and subsequent intellectual functioning.

\section{Methods}

SUBJECTS

The study sample consisted of 30 children who had repair of TGA (median age at surgery $7 \cdot 5$ months, median age at review $10 \cdot 1$ years), 51 who had repair of tetralogy of Fallot (median age at surgery 23 months, median age at review 10.9 years), and 33 who had repair of a VSD (median age at surgery 11 months, median age at review 10.7 years). These children had been operated on at the Children's Hospital, Camperdown during the period 1972-82. Those who had cyanotic heart disease (tetralogy of Fallot and TGA) had surgery using the technique of profound hypothermia with circulatory arrest, as previously described by this unit. 14 During this period anaesthetic and surgical techniques remained constant. Children who had any postoperative complication likely to affect development, such as cerebrovascular accident, were excluded, as were children known to have any preoperative intellectual handicaps. There were six $(7 \%)$ 


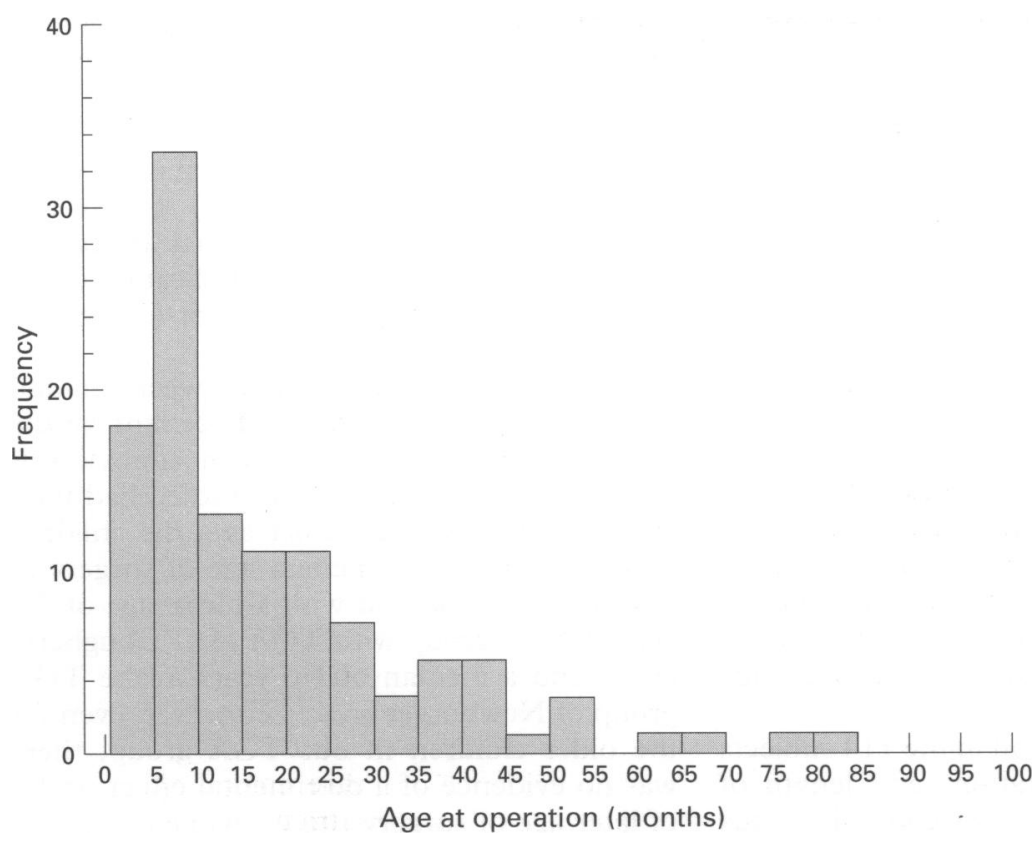

Figure 1 Distribution of age of corrective surgery for 114 children with congenital heart disease. necessary. IQ scores were not adjusted for sociodemographic variables.

The distribution of age at operation was found to be positively skewed, so a natural logarithm transformation was used. The effect of age at operation was then assessed by calculating the correlation between log (age at operation) and each of the outcome measurements. Spearman's rank correlation was used for variables that could not be transformed to normality (selective reminding and reaction time tests). All correlations were calculated for each diagnostic group separately. All results with two sided $\mathrm{p}$ values below 0.05 were regarded as statistically significant and are reported, although in interpreting them one must bear in mind that a large number of correlations were tested.

\section{Results}

There was no significant difference in the mean IQ scores of the three cardiac groups for full scale IQ (TGA 100; tetralogy of Fallot 100 ; VSD 102) or for the verbal or performance scores.

The distribution of age at operation was positively skewed (fig 1), but the distribution of $\log$ (age at operation) was not. No significant negative correlation was found between any component or subtest of IQ and log(age at operation) in any of the three diagnostic groups undergoing cardiac surgery (table, fig 2).

The only significant correlations between the neuropsychological measurements and $\log$ (age at operation) were in the group with tetralogy of Fallot for the Stroop test part C $(r=0.32 ; \mathrm{p}=0.02)$ and in the group with VSD for the Stroop test part B $(r=-0.51$; $\mathrm{p}=0.002)$, and the trail making test part $A$ $(r=0.37 ; \mathrm{p}=0.03)$, all adjusted for age and sex. Of these, only the last two (in the VSD group) indicate a detrimental effect of older age at operation, because high scores on the Stroop making test for visuomotor tracking ${ }^{15} 18$; the selective reminding test for memory function ${ }^{19}$; and reaction time. Because many of these test results are dependent on age, sex and socioeconomic status, a reference group of 51 schoolchildren, who were of similar age range and socioeconomic status ${ }^{20}$ and who had been free of major illness or surgery, was also assessed to determine the relationships between these variables and the neuropsychological measures.

\section{ANALYSIS}

The results for the reference group were used to determine relationships between each neuropsychological measure and age, sex, and socioeconomic status using linear regression. Some variables needed to be transformed first, by taking logarithms (trail making times) or square roots (Rey-Osterreith figure copy time) to make their distribution closer to normal. Regression equations containing only those variables found to be significant were then used to adjust the results for the study subjects for age, sex, and socioeconomic status as

Figure 2 Intelligence scores (WISC-R) on follow up plotted against age at operation on a logarithmic scale for 114 children with congenital heart disease. $T G A=$ transposition of the great arteries; $T E T=$ tetralogy of Fallot; $V S D=$ ventricular septal defect. 
Correlations between log (age at operation) and components of IQ (WISC-R), showing no significant negative correlations between $I Q$ and log(age at operation)

\begin{tabular}{|c|c|c|c|}
\hline Diagnostic group & $\begin{array}{l}T G A \\
(n=30)\end{array}$ & $\begin{array}{l}\text { Tetralogy of Fallot } \\
(n=51)\end{array}$ & $\begin{array}{l}V S D \\
(n=33)\end{array}$ \\
\hline Full scale IQ & $0 \cdot 14$ & $0 \cdot 27$ & 0.07 \\
\hline Verbal IQ & $0 \cdot 17$ & $0 \cdot 19$ & 0.09 \\
\hline Performance IQ & 0.06 & $0 \cdot 26$ & -0.002 \\
\hline Verbal communication (subtests $1,2,4,5$ ) & $0 \cdot 17$ & $0 \cdot 16$ & $0 \cdot 11$ \\
\hline Perceptual organisation (subtests $7,8,9,10$ ) & 0.06 & $0 \cdot 32^{\star}$ & $0 \cdot 11$ \\
\hline Freedom from distractibility (subtests $3,6,11$ ) & 0.08 & 0.01 & $-0 \cdot 16$ \\
\hline
\end{tabular}

${ }^{\star} \mathrm{p}=0.02$.

tests reflect good ability on this test, while greater trail making times indicate poorer ability in this area. As a final check, the results for the 81 children in the two cyanotic groups (TGA and tetralogy of Fallot) were combined, but again there was no evidence of a relationship between poorer test scores and older age at surgery.

No correlation was found in the 114 subjects between $\log$ (age at operation) and length of arrest time $(r=0.05)$ or socioeconomic status $(r=0 \cdot 10)$.

\section{Discussion}

If children with cyanotic congenital heart disease are at risk of falling IQ from chronic hypoxia, one would expect a negative correlation between IQ and age of surgery in the cyanotic (tetralogy of Fallot and TGA) group, but not in the acyanotic VSD group. In contrast with earlier studies ${ }^{8912}$ we found no evidence of a negative correlation between IQ and age of surgery in children with cyanotic congenital heart disease. This finding included the subtests of the WISC-R where Newburger et al (using the WPPSI) found the verbal, block design, picture completion, and geometric design scores to be negatively correlated with age of repair, ${ }^{12}$ and where O'Dougherty et al (using the WISC-R) found that the factor freedom from distractibility was negatively correlated with age at repair. Similarly, no negative correlations between age of surgery and neuropsychological tests were found in the cyanotic (tetralogy of Fallot and TGA) groups.

The only correlations which could indicate a detrimental effect of older age at surgery were found in the group with VSD. These were in the ability to move from one perceptual set to another (Stroop test) and in visuomotor tracking (trail making test). However, even these results should be regarded with caution. The number of neuropsychological measures and various subtests of the WISC-R meant that 35 correlations were tested in each diagnostic group. One would not be surprised that two results, 'significant' at the $5 \%$ level would appear just by chance when such a large number of correlations were tested.

What is the reason for the discrepancy between this and other studies? ${ }^{8912}$ In one of the papers by O'Dougherty et al, ${ }^{9}$ the discrepancy may be due to a statistical error. These authors state that 'nearly twice as many hypoxic children obtained IQ scores in the superior range and above, whereas the incidence of mental retardation was nearly three times that expected in the normal population'. However, these claims are based on only five and two children respectively, an insufficient number to obtain statistical significance. Their statement that the frequency distribution of IQ scores in their hypoxic (TGA) group was significantly different from normal appears to derive from an inappropriate application of the $\chi^{2}$ test to very small frequencies or to percentages.

There are other differences between this and the earlier studies which could account for the discrepant findings. One of the most obvious is that some of the children we studied had their cardiac surgery at an earlier age, the children with TGA having a median age of surgery of $7 \cdot 5$ months compared with a mean age of $2 \cdot 0$ years for the group with TGA of O'Dougherty et $a l^{9}$ and a median of 1.6 years in the TGA group of Newburger et al. ${ }^{12}$ However, even for the older children in our TGA group, there was no evidence of a detrimental effect on IQ of later age of surgery (fig 2), while our group with tetralogy of Fallot, who were operated on at a median age of 1.9 years, more like the ages of the cyanotic children in the earlier studies, also showed no evidence of a negative relationship between age of surgery and intelligence or neuropsychological abilities.

Another difference is that the children in the earlier studies had their surgery using cardiopulmonary by-pass, while our children with tetralogy of Fallot and TGA all had surgery performed using the technique of deep hypothermia and cardiac arrest. However, this is unlikely to account for the lack of correlation between later surgery and falling IQ as we found no association between arrest time and $\log$ (age at operation), and, if anything, deep hypothermia with cardiac arrest seems to pose a greater risk of brain malfunction. ${ }^{21-25}$

As intelligence testing in older children (the median age of the children when tested in this study was greater than 10 years in each group) is more likely to be accurate than in young children, such as the median age of 1.6 years in Newburger's series, ${ }^{12}$ it is possible that young age was a confounding factor that influenced results in earlier studies. In our study there was no possible confounding effect of socioeconomic status, as age of surgery was not correlated with this index. Newburger et al had to adjust for this variable because in their study patients operated on at an early age were of higher socioeconomic status than those repaired later. ${ }^{12}$

In summary, we found that, in children with TGA operated on at a median age of 7.5 months and in children with tetralogy of Fallot having surgery at a median age of 1.9 years, there was no evidence from intelligence testing, or neuropsychological testing, that the length of time these children were hypoxic before surgery had any adverse effect on their intellectual development.

While most children with cyanotic congenital heart disease have corrective surgery at as early an age as possible, with the trend to earlier surgery there are sometimes medical, social, or economic reasons (particularly in 
developing countries) which cause a delay in the timing of surgery. Although prolonged periods of chronic hypoxia have been shown to interfere with intellectual development, ${ }^{5}$ it appears from this study that relatively short delays in the timing of surgery should not be a cause for concern with regard to subsequent intellectual functioning.

This research was supported by a grant from the National Health and Medical Research Council of Australia.

1 Grant I, Heaton RK, McSweeney AJ, Adams KM, Timms RM. Neuropsychologic findings in hypoxemic chronicRM. Neuropsychologic findings in hypoxemic chronic-
obstructive pulmonary disease. Arch Intern Med 1982; 142: $1470-6$.

2 Prigatano GP, Parsons O, Wright E, Levin DC, Hawryluk G. Neuropsychological test performance in mildly hypoxemic patients with chronic obstructive pulmonary disease. F Consult Clin Psychol 1983; 51: 108-16.

3 Linde LM, Rasof B, Dunn O. Mental development in congenital heart disease. $\mathcal{F}$ Pediatr 1967; 71: 198-203.

4 Rosenthal A. Visual simple reaction time in cyanotic heart disease. Am f Dis Child 1967; 114: 139-43.

5 Rasof B, Linde LM, Dunn OJ. Intellectual development in children with congenital heart disease. Child Dev 1967; 38: 1043-53.

6 Feldt RH, Ewart JC, Stickler GB, Weidman WH. Children with congenital heart disease. Am $\mathcal{F}$ Dis Child 1969; 117: with con

7 Silbert A, Wolff PH, Mayer B, Rosenthal A, Nada AS. Cyanotic heart disease and psychological development. Pediatrics 1969; 43: 192-200.

8 O'Daugherty M, Wright FS, Garmezy N, Lowenson RB, Torres F. Later competence and adaptation in infants who survive severe heart defects. Child Dev 1983; 54: 1129-42.

9 O'Dougherty M, Wright FS, Loewenson RB, Torres F. Cerebral dysfunction after chronic hypoxia in children. Neurology 1985; 35: 42-6.

10 Wechsler D. Manual for the Wechsler intelligence scale for children - revised. New York: Psychological Corporation, 1974.

11 Kaufman AS. Factor analysis of the WISC-R at 11 age levels between $6 \frac{1}{2}$ and $16^{1 / 2}$ years. F Consult Clin Psychol 1975; 43: 135-47.
12 Newburger JW, Silbert AR, Buckley LP, Fyler DC. Cognitive function and age at repair of transposition of the
great arteries in children. $N$ Engl $f$ Med 1984; 310: great arter.

13 Wechsler D. Wechsler preschool and primary scale of intelligence. New York: Psychological Corporation, 1967.

4 Tharion J Johnson DC, Celemaier JM, Hawker RM, Cartmill TB, Overton JH. Profound hypothermia with circulatory arrest. 7 Thorac Cardiovasc Surg 1982; 84: 66-72.

15 Lezak MD. Constructional functions. Neurological assessment. 2nd Ed. New York: Oxford University Press, 1983 $382-413$

16 Miller E. Verbal fluency as a function of a measure of verbal intelligence and in relation to different types of cerebral pathology. Br f Clin Psychol 1984; 23: 53-7.

17 Golden CJ. Identification of brain disorders by the Stroop color and word test. $₹$ Clin Psychol 1976; 32: 654-8.

18 Reitan RM. Trial making test results for normal and brain-damaged children. Percept Mot Skills 1971; 33: 575-81

19 Buschke H, Fuld PA. Evaluating storage, retention and retrieval in disordered memory and learning. Neurology 1974; 24: 1019-25.

20 Congalton AA. Social standing of occupation in Australia. Studies in sociology No 3. Kensington, Sydney: University of New South Wales, 1963.

21 Wells FC, Coghill S, Caplan HL, Lincoln C, Kirklin JW. Duration of circulatory arrest does influence the psychoogical development of children after cardiac operation in early life. F Thorac Cardiovasc Surg 1983; 86: 823-31.

22 Rossi $R$ Eloth $R$ Linclion $C$, injury after total  mia by estimation of specific creatinine kinase isoenzyme levels using monoclonal

23 Ekroth R, Thompson RJ, Lincoln C, Scallan M, Rossi R, Tsang V. Elective deep hypothermia with total circulatory arrest: changes in plasma creatinine kinase $\mathrm{BB}$, blood glucose and clinical variable. $\mathcal{F}$ Thorac Cardiovasc Surg 1989; 97: 30-5.

24 Rossi R, Van der Linden J, Ekroth R, Scallan M, Thompson RJ, Lincoln C. No flow or low flow? A study of ischemic marker creatinine kinase BB after deep hyothermic procedures. F Thorac Cardiovasc Surg 1989; 98: 193-9.

25 Greeley WJ, Ungerleider RM, Smith LR, Reeves JG. The effects of deep hypothermic cardiopulmonary bypass and total circulatory arrest on cerebral blood flow in i and children 7 Thorac Cardiovasc Surg 1989; 97 737-45. 